\title{
FIRST REPORT OF OPHICHTHUS MACHIDAI (ACTINOPTERYGII: ANGUILLIFORMES: OPHICHTHIDAE) FROM THE INDIAN OCEAN
}

\author{
Anil MOHAPATRA ${ }^{1 *}$, Dipanjan RAY ${ }^{2}$, Swarup R. MOHANTY1 ${ }^{1}$, and Subhrendu S. MISHRA ${ }^{3}$ \\ ${ }^{1}$ Estuarine Biology Regional Centre, Zoological Survey of India, Gopalpur-on-Sea, Ganjam, Odisha, India \\ ${ }^{2}$ Bajkul Milani Mahavidyalaya, Kismat Bajkul, Purba Medinipur, West Bengal, India \\ ${ }^{3}$ Marine Fish Section, Zoological Survey of India, Kolkata, India
}

\begin{abstract}
Mohapatra A., Ray D., Mohanty S.R., Mishra S.S. 2019. First report of Ophichthus machidai (Actinopterygii: Anguilliformes: Ophichthidae) from the Indian Ocean. Acta Ichthyol. Piscat. 49 (1): 49-51.

Abstract. The Machida's snake eel, Ophichthus machidai McCosker, Ide et Endo, 2012, is reported for the first time from the coasts of Bay of Bengal, India. Four specimens (396-457 mm total length) were collected from the Shankarpur fishing harbour, Digha, West Bengal. Principal morphological characters were determined and the specimen was illustrated and described. The species was previously restricted to the northern Pacific Ocean and now is reported for the first time from the Indian coast of the Indian Ocean.
\end{abstract}

Keywords: east coast of India, fish, new record, morphology, snake eel, Ophichthinae

\section{INTRODUCTION}

The family Ophichthidae is represented by 339 valid species worldwide and comprises two subfamilies, the Myrophinae (69 valid species) and the Ophichthinae (270 valid species) (Fricke et al. 2018). In Indian waters, the family Ophichthidae is represented by 17 genera and 24 species (Gopi and Mishra 2015). Among the eels of the subfamily Ophichthinae the genus Ophichthus contains the highest numbers of species of the 47 currently recognized genera. The genus Ophichthus is represented by five species in the Indian coastal waters (Talwar and Kacker 1984, Ray et al. 2015), i.e., Ophichthus altipennis (Kaup, 1856), Ophichthus apicalis (Anonymous [Bennett], 1830), Ophichthus cephalozona Bleeker, 1864, Ophichthus lithinus (Jordan et Richardson, 1908), and Ophichthus microcephalus (Day, 1878).

The Machida's snake eel, Ophichthus machidai McCosker, Ide et Endo, 2012 was described from Japan (McCosker et al. 2012). In 2013 it was reported from Yi-lan, Taiwan (Chiu et al. 2013), indicating that the presence of the species along the north-western Pacific region may be wider. While working on some eel specimens from Bay of Bengal along Indian coast, we came across four specimens of the genus Ophichthus, which were identified as Ophichthus machidai. This paper constitutes the first report of the Machida's snake eel from Indian waters and the first record from the Indian Ocean. The details of the morphometric and meristic characters of $O$. machidai from Indian waters are given below.

\section{MATERIAL AND METHODS}

Four specimens of Ophichthus machidai (396-457 mm total length) were collected from the Shankarpur fishing harbour, Digha, West Bengal. The fishermen, landing their catch in Digha, usually operate within the Exclusive Economic Zone of India. Abbreviations used in the description are DFO (dorsal-fin origin), HL (head length), and TL (total length). The measurements and head pore terminology follow McCosker et al. (1989). The generic allocation follows Smith and McCosker (1999). All measurements (except the total length, measured to the nearest $1 \mathrm{~mm}$ ) were recorded to the nearest $0.1 \mathrm{~mm}$ and taken using digital callipers. Head pores and teeth were counted using a Leica EZ4 microscope. Vertebrae were counted by digital radiographs and expressed as in Böhlke (1982). The specimens are deposited in the Estuarine Biology Regional Centre, Zoological Survey of India, Gopalpur-on-Sea, Odisha, India.

\section{RESULTS}

\section{Family OPHICHTHIDAE}

Ophichthus machidai McCosker, Ide et Endo, 2012

(Figs. 1, 2; Table 1)

Description. Body moderately elongated with preanal length of 2.2-2.3 in TL, dorsal fin origin slightly behind pectoral fin tip in 3 specimens, where as in one specimen it is above pectoral fin. Pre-dorsal length 7.9-8.5 in TL, pectoral fin well developed and elongated, longer than jaw. Snout pointed and 5.4-5.7 in HL, upper jaw larger than lower jaw, anterior nostril small, tubular and not reaching tip of snout. Posterior nostril elongate slit, opening towards mouth, not 
visible along margin of lip. Single barbel between anterior and posterior nostrils. Underside of snout with numerous minute fleshy bristles in ethmoidal region. Head 10.1-10.6 in TL. Rictus beneath rear margin of eye. Eye diameter 8.6-9.8 in HL. Head pores small, inconspicuous (Fig. 2). Single interorbital and temporal pores, supraorbital pores (SOP) $1+4$, infraorbital pores (IOP) $2+4$, mandibular pores 5, preopercular pores 3 (both mandibular pores and preopercular pores together termed as preoperculo mandibular pore or POM ) in all specimens. Lateral-line (LL) pores very minute, 9 before gill opening (GO). Teeth conical, small, (Fig. 3). Five intermaxillary teeth with irregularly biserial patch followed by gap. Maxillary teeth uniserial, 29-31 closely set teeth on each side becoming smaller posteriorly. Vomerine teeth uniserial up to 5-7 teeth followed by 6 pairs of biserial teeth followed by uniserial 5-6 teeth. Mandibular teeth clearly uniserial with 36-39 teeth on each side. Predorsal vertebrae 12-13, preanal vertebrae 58-59, and total vertebrae 153-156.

Colour of the specimen is brown above lateral midline and pale ventrally in formalin preserved specimens. Lower lip anterior chin region and anterior nostril dark.

\section{DISCUSSION}

In having uniform (brown tan) body colour, the dorsal fin origin above or slightly behind the pectoral-fin tip and uniserial lower jaw teeth, Ophichthus machidai can be placed in a group of 11 species. Of these, Ophichthus aniptocheilos McCosker, 2010, Ophichthus grandoculis (Cantor, 1849), Ophichthus longipenis McCosker et Rosenblatt, 1998, Ophichthus manilensis Herre, 1923, Ophichthus mecopterus McCosker et Rosenblatt, 1998, and Ophichthus tsuchidae Jordan et Snyder, 1901 differ by having biserial maxillary teeth, at least posteriorly. Further, O. aniptocheilos and O. mecopterus have fewer vertebrae (139-146) and $O$. longipenis has more vertebrae (176-184). Ophichthus ishiyamorum McCosker, 2010 and $O$. apicalis also have fewer vertebrae (130-132 and 136-139). Like O. apicalis, Ophichthus obtusus McCosker, Ide et Endo, 2012 has a second labial barbel below the orbit (total two labial barbels), though the vomerine teeth pattern and rictus position (below posterior margin of eye or slightly behind) is similar to that of O. machidai specimens (McCosker et al. 2012). As observed in McCosker et al. (2012), Ophichthus habereri Franz, 1910 is distinct from O. obtusus in having its eye position slightly more anterior and the length of its jaw is considerably longer, which clearly differentiated from $O$. machidai too.

Ophichthus machidai was described on the basis of 23 specimens from Japan (McCosker et al. 2012) and later, it was reported from Taiwan (Chiu et al. 2013) on the basis

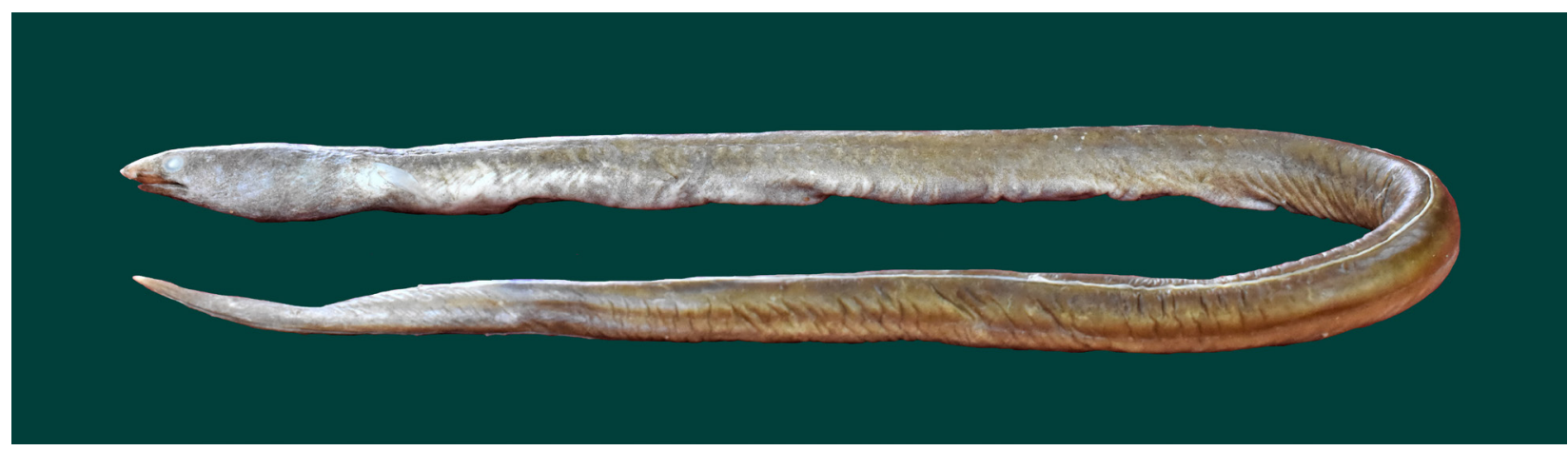

Fig. 1. Ophichthus machidai from Bay of Bengal, India (Reg. No. EBRC/ZSI/F 10205; TL - 457 mm)

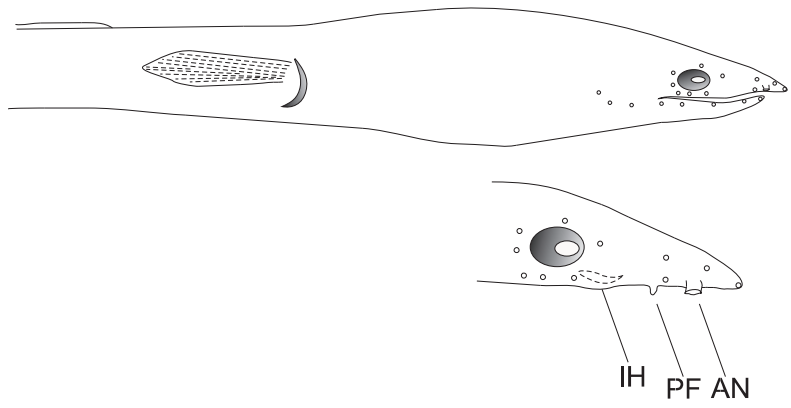

Fig. 2. Head pores, nostril and dorsal fin origin of Ophichthus machidai; $\mathrm{IH}=$ inner hole of posterior nostril, $\mathrm{PF}=$ projected flap, $\mathrm{AN}=$ anterior nostril

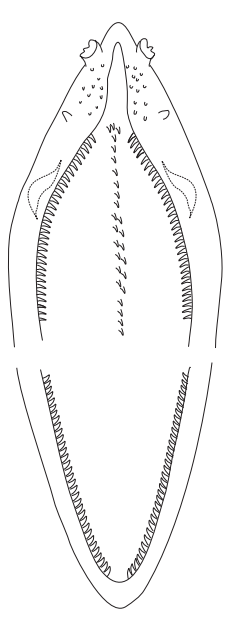

Fig. 3. Teeth pattern in Ophichthus machidai, collected from Bay of Bengal, India 
Table 1 REFERENCES

Comparative characters in Ophichthus machidai from Pacific Ocean and Indian Ocean

\begin{tabular}{lccc}
\hline \multicolumn{1}{c}{ Character } & $\begin{array}{c}\text { Presently } \\
\text { reported study }\end{array}$ & $\begin{array}{c}\text { McCosker et } \\
\text { al. 2012 }\end{array}$ & $\begin{array}{c}\text { Chiu et al. } \\
2013\end{array}$ \\
\hline Depth at GO in TL & $32.1-38.1$ & $27-40$ & - \\
Preanal length in TL & $2.2-2.3$ & $2.1-2.6$ & - \\
Head length in TL & $10.1-10.6$ & $10-12$ & - \\
Eye in HL & $8.6-9.8$ & $7.3-11.3$ & - \\
Predorsal vertebrae & $12-13$ & $11-16$ & 13 \\
Preanal vertebrae & $58-59$ & $52-59$ & 58 \\
Total vertebrae & $153-156$ & $150-161$ & 162 \\
SOP & $1+4$ & $1+4$ & $1+4$ \\
IOP & $4+2$ & $4+2$ & $4+2$ \\
POM & $5+3$ & $5+2$ or 3 & $5+2$ \\
LL before GO & 9 & 9 & 9 \\
\hline
\end{tabular}

$\mathrm{TL}=$ total length, $\mathrm{GO}=$ gill opening, $\mathrm{HL}=$ head length, $\mathrm{SOP}=$ number of supraorbital pores, IOP $=$ number of infraorbital pores, $\mathrm{POM}=$ number of preoperculo mandibular pores, $\mathrm{LL}=$ number of lateral-line pores.

of five specimens. However, Taiwanese specimens were described as having the dorsal-fin origin behind or slightly behind the middle of the pectoral fin and vomerine teeth biserial anteriorly, becoming uniserial posteriorly (Chiu et al. 2013), deviating from the original description of the Japanese specimens. A detail of comparative characters of the specimens from Japan and Taiwan with Indian Ocean species is given in Table 1. Until now, the species was known from northwest Pacific region and the present report extends its range. The preopercular pores of the Japanese specimens were two and rarely three McCosker et al. (2012), but all currently examined specimens from India have three preopercular pores. The majority of the morphometric ratios, teeth pattern, and other characters almost match the description of them in McCosker et al. (2012).

\section{ACKNOWLEDGEMENTS}

The authors are thankful to Dr Kailash Chandra, Director, Zoological Survey of India, for providing necessary working facilities and encouragement. We extend our gratitude to Dr David G. Smith, Smithsonian Institution, Museum Support Center and Dr John E. McCosker, California Academy of Sciences, for their magnanimous support in providing required literature.
Böhlke E.B. 1982. Vertebral formulae of type specimens of eels (Pisces: Anguilliformes). Proceedings of the Academy of Natural Sciences of Philadelphia 134: 31-49.

Chiu Y.-C., Lin J., Chen H.-M. 2013. One new record genus and three new record species of snake eels (Ophichthidae: Anguilliformes) from Taiwan. Journal of Marine Science and Technology 21 (1): 201-206. DOI: 10.6119/JMST-013-1220-10

Fricke R., Eschmeyer W.N., Fong J.D. 2018. Catalog of fishes: Species by family/subfamily. [Accessed on 15 December 2018.] http://researcharchive.calacademy. org/research/ichthyology/catalog/SpeciesByFamily. asp.

Gopi K.C., Mishra S.S. 2015. Diversity of marine fishes of India. Pp.171-194. In: Venkataraman K., Sivaperuman C. (eds.) Marine faunal diversity in India: Taxonomy, ecology and conservation. Academic Press, San Diego CA, USA.

McCosker J.E., Böhlke E.B., Böhlke J.E. 1989. Family Ophichthidae. Pp. 254-412. In: Böhlke E.B. (ed.) Fishes of the western North Atlantic, No. 1, Part 9, Vol. 1. Memoirs of the Sears Foundation for Marine Research, Yale University, New Haven CT, USA.

McCosker J.E., Ide S., Endo H. 2012. Three new species of ophichthid eels (Anguilliformes: Ophichthidae) from Japan. Bulletin of the National Museum of Nature and Science, Series A (Zoology) (Suppl. 6): 1-16.

Ray D., Mohapatra A., Biswas S., Satpathy K.K., Mishra S.S. 2015. First record of the Evermann's snake eel, Ophichthus lithinus (Actinopterygii: Anguilliformes: Ophichthidae), from northern Indian Ocean. Acta Ichthyologica et Piscatoria 45 (1): 89-93. DOI: 10.3750/AIP2015.45.1.10

Smith D.G., McCosker J.E. 1999. Ophichthidae, snake eels, worm eels. Pp. 1662-1669. In: Carpenter K.E., Niem V.H. (eds.) FAO species identification guide for fishery purposes. The living marine resources of the Western Central Pacific. Volume 3. Batoid fishes, chimaeras and bony fishes, Part 1 (Elopidae to Linophrynidae). FAO, Rome.

Talwar P.K., Kacker R.K. 1984. Commercial sea fishes of India. Zoological Survey of India, Calcutta, India.

Received: 23 July 2018

Accepted: 30 August 2018

Published electronically: 15 March 2019 